\title{
Migraine: association with personality characteristics and psychopathology
}

\author{
SD Silberstein ${ }^{1}$, RB Lipton ${ }^{2}, \mathrm{~N}^{\text {Breslau}}{ }^{3}$
}

\begin{abstract}
Comprehensive Headache Center ${ }^{1}$, Germantown Hospital and Medical Center, Temple University School of Medicine, Philadelphia, PA, USA; Montefiore Medical Center ${ }^{2}$, Albert Einstein College of Medicine, Bronx, NY, USA; Departments of Psychiatry ${ }^{3}$ Henry Ford Hospital, Detroit, MI and Psychiatry, School of Medicine, Case Western Reserve University, Cleveland, OH and the School of

Medicine, University of Michigan, Ann Arbor, MI, USA
\end{abstract}

\section{Cephalalgia}

Silberstein SD, Lipton RB, Breslau N. Migraine: association with personality characteristics and psychopathology. Cephalalgia 1995;15:358-69. Oslo. ISSN 0333-1024

The relationship between migraine and psychopathology has been discussed far more often than it has been systematically studied. Twentieth-century investigators have frequently described the obsessional, rigid, angry personality postulated to characterize migraine sufferers. More recent population-based studies have demonstrated associations between migraine and depression and migraine and panic disorder. This article discusses the relationship of migraine and personality and migraine and psycho-pathology. - Cormorbidity, depression, dysthymia, mania, migraine, panic disorder, personality, psychopathology

Stephen D. Silberstein, One Penn Boulevard, Philadelphia, PA 19144, USA. Tel. +1 215 951-8926, fax. +1 215 843-8935. Received 21 November 1994, accepted 23 February 1995

The relationship between migraine and psycho-pathology has been discussed far more often than it has been systematically studied. One ancient view suggests that migraine was caused by evil spirits. More recently, Andrew Pope, in The Rape of the Lock, suggested a relationship between depression (spleen) and migraine.

When screen'd in shades from day's detested glare, Spleen sighs forever on her pensive bed, Pain at her side, and megrim at her head (1).

Twentieth-century investigators have frequently described the obsessional, rigid, angry personality postulated as characterizing migraine sufferers (2). More recent population-based studies have demonstrated associations between migraine and depression and migraine and panic disorder.

In this article, we discuss the relationship of migraine and personality and migraine and psychopathology. After addressing the methodologic issues important to these studies, we review both clinic-based and population-based data. We close with a summary of alternative explanations for the association between migraine and psychopathology and speculate on the mechanism of the association.

Methodologic issues

\section{Selection bias}

Many early studies of migraine and psychopathology were conducted in subspecialty centers. As most migraine sufferers do not receive a medical diagnosis and only $2 \%$ consult headache specialists, observations from subspeciality clinics are subject to referral bias $(3,4)$. Factors that lead to consulting headache specialists may be mistaken for attributes of the disease (5- 7). If patients with obsessional personality traits are more likely to seek out specialists, obsessional personalities may be over-represented among migraine sufferers who attend a headache-clinic (8). Even if migraine and obsessional personality are not associated, they might appear to be associated in a clinic-based sample. Thus, findings from clinic-based samples must be confirmed in samples of the general population before they are accepted as valid. Henryk-Gutt and Rees found that migraineurs selected from headache clinics had more psychopathology than migraineurs identified by screening civil servants in London (9).

\section{Diagnosis and measurement}

Case-definitions of migraine have varied substantially across studies. While some studies have relied on a clinician's implicit diagnosis without specifying diagnostic criteria, others have used the imprecise ad hoc criteria developed by Friedman et al. (10). A few recent studies have used the explicit diagnostic criteria proposed by the International Headache Society (IHS) (11), but even these criteria have important limitations $(12,13)$.

Studies have also varied in their approaches to assessing personality or psychopathology. Personality (patterns of perceiving, relating to, and thinking about the environment and oneself that are exhibited in a wide range of social and personal contents) refers to relatively stable individual characteristics that vary along a continuum without any direct 
implication about abnormal function (14). Psychopathology refers to marked deviations from normal function (15). Personality characteristics and psychopathology can both be assessed using dimensional or categoric systems of measurement. Diagnostic systems for headache (IHS) and for psychopathology (DMS-IV) use categoric systems to identify individuals with specific disorders, such as migraine, major depression, or panic disorder (16). A contrasting approach, which grew out of the psychometric research, measures personality characteristics or psychopathology using dimensional scales (16). In general, it is easier to detect statistically significant group differences (between migraine and non-migraine groups) using dimensional rather than categoric variables.

\section{Migraine and personality}

\section{Introduction}

Over the years, many studies have focused on particular personality traits of migraineurs. Basic assumptions are that: (i) migraineurs share common personality traits, (ii) these traits are enduring and measurable, and (iii) these traits differentiate migraineurs from controls (17). The notion of a migraine personality first arose from clinical observations of the highly selected patients seen in sub-specialty clinics.

In 1934, Touraine and Draper (18) reported that migraineurs were deliberate, hesitant, insecure, detailed, perfectionistic, sensitive to criticism, and deeply frustrated emotionally. They were said to lack warmth and to have difficulty making social contacts. Wolff found his migraineurs to be rigid, compulsive, perfectionistic, ambitious, competitive, chronically resentful, and unable to delegate responsibility (2). They had troubled relationships with their parents, protected themselves from intimacy, and attempted to dominate their environment. Friedman reported that some, but not all, of his migraineurs were orderly, overly conscientious, and meticulous in appearance. He observed that patients with migraine showed hostility, irritability, withdrawn social behaviour, and transitory and prolonged depressions (19).

While these descriptions are based on uncontrolled observation of highly biased patient samples, they have passed into the general culture. For example, in The White Album, Joan Didion's physician focuses on aspects of the migraine personality: "You don't look like a migraine personality ... Your hair's messy. But I suppose you're a compulsive housekeeper" (20). Her response reflects a higher level of scientific rigor than her physician's question: "Actually my house is kept even more negligently than my hair." But the doctor was right nonetheless; perfectionism can also take the form of spending most of a week writing and rewriting a paragraph. But not all perfectionists have migraine, and not all migrainous people have migraine personalities (20).

Didion's comment gets to the essence of the matter. Do migraineurs have enduring personality profiles different from those of the general population? The migraine personality has rarely been investigated in population-based samples of patients. This review focuses on studies of population or general practice samples to avoid the problems of selection bias that limit findings from clinic-based studies. Studies using the Minnesota Multiphasic Personality Inventory (MMPI) are addressed in a separate section.

\section{Population-based studies (Table 1)}

Most investigations have used psychometric instruments such as the MMPI or the Eysenck Personality Questionnaire (EPQ). The EPQ is a well-standardized measure which includes four scales: psychoticism (P), extroversion $(\mathrm{E})$, neuroticism $(\mathrm{N})$, and lie $(\mathrm{L})$.

Brandt et al. (21) used the Washington County Migraine Prevalence study to conduct the first population-based case-control study of personality in migraine (Table 1). Over 10000 12- to 29-year-olds selected using random-digit dialing received a diagnostic telephone interview. A sample of subjects who met the criteria for migraine with or without aura $(n=162)$ were compared to subjects without migraine. Each subject received the $E P Q$, the 28-item version of the General Health Questionnaire (GHQ), and a question about headache laterality.

Subjects with migraine scored significantly higher than controls on the EPQ N scale, indicating that they were more tense, anxious, and depressed than the control group. In addition, women with migraine scored significantly higher on the P scale than controls, indicating that they were more hostile, less interpersonally sensitive, and out of step with their peers. Both men and women with migraine had significantly lower mean $L$ scores than controls, suggesting that they were less defensive than the control group. Migraine sufferers of both sexes scored significantly higher than controls on the GHQ, with higher levels of anxiety, insomnia and depression, and more somatic complaints and social dysfunction.

Rasmussen (22) screened a population-based sample to identify migraine and tension-type headache (TTH) sufferers, with classification based on clinical assessment using the IHS criteria. They found no association between these disorders and cohabitation, employment status, marital status, educational level, or occupational category. TTH occurring alone was associated with high N scores on the EPQ. Persons with pure migraine (that is, without TTH) did not score above the norms on the $\mathrm{N}$ scale, although persons with migraine, with and without 
Table 1. Migraine and personality: epidemiologic studies (community).

\begin{tabular}{|c|c|c|c|c|c|c|}
\hline & Subiects & & Sample & & & \\
\hline $\begin{array}{l}\text { Brandt et al., } \\
1990(21)\end{array}$ & $\begin{array}{l}N \text { DX } \\
162 \mathrm{Mig} \\
\mathrm{RR}=94.2 \%\end{array}$ & $\begin{array}{c}\text { Age } \\
12-29\end{array}$ & $\begin{array}{l}\text { Source } \\
\text { Community } \\
\text { telephone } \\
\text { survey of } \\
10,169\end{array}$ & $\begin{array}{c}\text { Controls } \\
162 \text { matched } \\
\text { for sex and } \\
\text { age-no } \\
\text { headache }\end{array}$ & $\begin{array}{c}\text { instrument } \\
\text { EPQ }\end{array}$ & $\begin{array}{l}\text { Findings } \\
\text { EPQ-N: Both F \& M Mig higher } \\
\text { than controls. } \\
\text { EPQ-P: F Mig higher than } \\
\text { controls. }\end{array}$ \\
\hline $\begin{array}{l}\text { Rasmussen } \\
1992(22)\end{array}$ & $\begin{array}{l}77 \mathrm{Mig} \\
167 \mathrm{TTH} \\
\mathrm{RR}=76 \%\end{array}$ & $25-64$ & $\begin{array}{c}\text { Random sample } \\
\text { of } 1000 \\
\text { selected from } \\
\text { the National } \\
\text { Central } \\
\text { Person } \\
\text { Registry }\end{array}$ & $\begin{array}{c}496 \text { non- } \\
\text { headache }\end{array}$ & EPQ & $\begin{array}{l}\text { EPQ-N: } \\
\text { (1) Higher for TTH and Mig } \\
\text { vs rest. } \\
\text { (2) No difference b/t "pure" mig } \\
\text { vs rest. }\end{array}$ \\
\hline $\begin{array}{l}\text { Merikangas } \\
\text { et al., } 1993 \\
\text { (23) }\end{array}$ & $\begin{array}{l}11 \text { Cls } \\
91 \text { Corn } \\
63 \text { TTH } \\
50 \text { Sxs } \\
\text { Only }\end{array}$ & $28-29$ & $\begin{array}{l}\text { Community } \\
\text { survey in } \\
\text { Zurich- } \\
\text { longitudinal }\end{array}$ & $\begin{array}{l}158 \text { non- } \\
\text { headache }\end{array}$ & $\begin{array}{c}\text { Freiburg } \\
\text { Personality } \\
\text { Inventory }\end{array}$ & $\begin{array}{l}\text { Cls sign. higher than other } \\
\text { groups } \\
\text { on nervousness, } \\
\text { depressiveness, } \\
\text { inhibition, decreased levels of } \\
\text { resilience. }\end{array}$ \\
\hline
\end{tabular}

Abbreviations: $\mathrm{Com}=$ common migraine; $\mathrm{Cls}=$ classic migraine; Combo $=$ combination; $\mathrm{EPQ}=$ Eysenck Personality Questionnaire; EPQ-E = EPQ: Extraversion; EPQ-N = EPQ: Neuroticism; EPQ-P = EPQ: Psychoticism; EPQ-L = EPQ: Lie; HA = headache; $M C=$ muscle contraction; Mig = migraine; Mixed = mixed headache type; $\mathrm{PT}=$ post trauma; $\mathrm{RR}=$ response rate; $\mathrm{SMCH}=$ scalp muscle contraction; $\mathrm{TTH}=$ tension type headache.

TTH, showed a tendency to score above the norms on the $\mathrm{N}$ scale. None of the headache groups showed any association with the $L$ scale. Clearly, the inclusive migraine group is more representative of migraine sufferers than the pure migraine group, as most migraineurs in that study also reported TTH. For this group, findings paralleled those of Brandt et al. on the $\mathrm{N}$ scale.

Merikangas et al. (23) investigated the cross-sectional association between personality, symptoms, and headache subtypes as part of a prospective longitudinal study of 19- and 20-year-olds in Zurich, Switzerland, when the subjects were 29 to 30 years old. Personality was assessed by the Freiburg Personality Inventory (FPI). The symptoms checklist 90 (SCL-90) was used to examine somatic and psychologic symptoms. Migraineurs scored higher on indicators of neuroticism than did non-migraine subjects. This difference reached statistical significance only in subjects with migraine with aura $(n=11)$. Somatization was the only subscale on the SCL-90 which discriminated between subjects with migraine and those without migraine. TTH subjects did not differ from controls on any of the personality or symptom scales.

\section{Samples of convenience (Tables 2 and 3 )}

Passchier et al. (25) recruited adult headache patients and healthy control subjects through advertisements in a local newspaper (Table 2). Subjects with headache disorders were offered behavioral therapy, while control subjects were paid. Migraine and TTH subjects both showed elevated achievement motivation, while rigidity was present mainly in the TTH group. Neither migraineurs nor TTH subjects showed elevations on the neuroticism or obsessive-compulsive scales. These findings are limited because the recruitment and incentive procedures may have introduced selection bias. Headache sufferers who desire behavioral therapy may have different psychologic profiles than do headache sufferers in general.

Passchier et al. $(24,25)$ studied a stratified sample of schoolchildren in Holland. About 57000 children were chosen, and headache was measured using Waters' headache questionnaire. Compared to children without headache, children with migraine and TTH were characterized by a high motivation to achieve and by a fear of failure (24).

Schmidt et al. (17) recruited subjects from a large metropolitan city in western Canada using a press release. From the initial screening, 125 subjects with migraine (103F, 22M) between the ages of 20 and 55 years were selected; all received the Jackson Personality Inventory. No differences were found between migraine sufferers and historical norms for anxiety, tension, or orderliness. Lower scores were found on complexity, risk-taking, and social participation scales and higher scores on responsibility and value orthodoxy scales. A potential response bias may have affected the results, as subjects who respond to a press release may differ from other migraine sufferers. Response bias might be especially likely because the study did not use a control group of persons who responded to a press release. 


\begin{tabular}{|c|c|c|c|c|c|c|c|}
\hline & $\begin{array}{l}\text { Subj } \\
\mathrm{N}\end{array}$ & DX & Age & Source & Controls & Instrument & Findings \\
\hline $\begin{array}{l}\text { Passchier } \\
\text { et al., } 1984 \\
\text { (25) }\end{array}$ & $\begin{array}{l}56 \\
32\end{array}$ & $\begin{array}{l}\text { Mig } \\
\text { TTH }\end{array}$ & $16-55$ & $\begin{array}{l}\text { Subjects } \\
\text { recruited by } \\
\text { ads in local } \\
\text { paper- } \\
\text { offered } \\
\text { therapy for } \\
\text { HA }\end{array}$ & $\begin{array}{l}26 \text { matched for } \\
\text { sex, age } \\
\text { non-medical } \\
\text { treatment, } \\
\text { and } \\
\text { education }\end{array}$ & $\begin{array}{l}\text { (1) Inadequacy and } \\
\text { rigidity } \\
\text { subscales from } \\
\text { the Dutch } \\
\text { Personality Q. } \\
\text { (2) Achievement } \\
\text { motivation test } \\
\text { (3) Inventory of } \\
\text { daily beh. } \\
\text { (4) Impulsiveness } \\
\text { scale (IMP) } \\
\text { Defense } \\
\text { Mechanism I. }\end{array}$ & $\begin{array}{l}\text { (1) Mig and TTH patients more } \\
\text { achievement oriented than } \\
\text { controls. } \\
\text { (2) TTH more rigid than controls. } \\
\text { (3) Combined groups more } \\
\text { rigidity, achievement } \\
\text { motivation, debilitating anxiety } \\
\text { and less impulsiveness than } \\
\text { controls. }\end{array}$ \\
\hline $\begin{array}{l}\text { Schmidt } \\
\text { et al., } 1986\end{array}$ & 125 & Mig & $18-55$ & $\begin{array}{l}\text { Recruited by } \\
\text { press release } \\
\text { announcing } \\
\text { study of Mig } \\
\text { HA }\end{array}$ & & $\begin{array}{l}\text { Jackson } \\
\text { Personality } \\
\text { Inventory } \\
\text { (16 scales) }\end{array}$ & $\begin{array}{l}\text { Complexity, responsibility, risk } \\
\text { taking, social participation, and } \\
\text { value orthodoxy lower for Mig } \\
\text { group than test norms. }\end{array}$ \\
\hline
\end{tabular}

Abbreviations: $\mathrm{Com}=$ common migraine; $\mathrm{Cls}=$ classic migraine; Combo- combination; $\mathrm{EPQ}=$ Eysenck Personality Questionnaire; EPQ-E = EPQ: Extraversion; EPQ-N = EPQ: Neuroticism; EPQ-P = EPQ: Psychoticism; EPQ-L = EPQ: Lie; $\mathrm{HA}=$ headache; $M C$ = muscle contraction; $\mathrm{Mig}=$ migraine; Mixed = mixed headache type; $\mathrm{PT}=$ post trauma; $\mathrm{RR}=$ response rate; $\mathrm{SMCH}=$ scalp muscle contraction; $\mathrm{TTH}=$ tension type headache.

Henryk-Gutt and Rees (9) interviewed a random sample of civil servants with migraine with aura, migraine without aura, non-migrainous headache, and non-headache to obtain information on personal, medical, and family histories (Table 3). Groups were matched for age, sex, marital status, and civil service grade. Migraineurs, compared to non-migraine headache patients and non-headache controls, had significantly increased $\mathrm{N}$ scores on the EPQ, increased anxiety and somatization scores on the MMPI (women only), and increased hostility scores on the Buss Scale. Women migraine clinic patients had even higher N scores, anxiety, and hostility scores (9), a finding that might reflect high rates of comorbid diseases among the clinic patients.

Phillips (26) studied patients with migraine and "muscular tension" headache. Questionnaires were mailed to a sample of approximately 1500 patients selected from a general practice register. A sample of 68 headache cases (the basis of selection is uncertain) completed the EPQ. The group consisted of 39 migraineurs, 24 muscular tension-headache patients, and 5 individuals with both conditions. (Migraine was defined by the presence of two or more of the following symptoms: unilateral headache, nausea and/or vomiting, and sensory prodromata. Muscular tension headache was defined as headache with no more than one of the above symptoms (with the exception of vomiting).) The groups did not differ from each other on N, E, P, or L scales of the EPQ. A different sample of tension-headache patients, selected on the basis of their desire for treatment and their headache severity, had significant elevation of $\mathrm{N}$ scores. Perhaps this was a sample of patients with transformed migraine (27), since the higher $\mathrm{N}$ score was associated with higher medication use. This study did not have non-headache controls and used historical norms.

Crisp et al. (28) surveyed every fifth adult from a group practice in a small English town (5000 adults). Patients were interviewed and given the Middlesex Hospital questionnaire. Women with migraine were significantly more anxious and depressed than were non-migraine subjects, many of whom had other headache types. (Diagnostic criteria for common migraine were a throbbing headache (unilateral or bilateral) associated with nausea and/or vomiting and/or severe photophobia. Classic migraine required a preceding "warning".) There was no control group.

Hundleby and Loucks compared 91 young adult migraineurs with 126 non-migraine controls recruited from students who completed a headache questionnaire. Measurements included the Personal Data Form, the 16P-F, the Jackson Personality Research Form (Form E), the Depression Adjective Checklist (Form A), stimulation-seeking scales, and other selected objective tests of personality. Anxiety and cortertia (a measure of alertness and arousal) scores were significantly higher in the migraineurs 


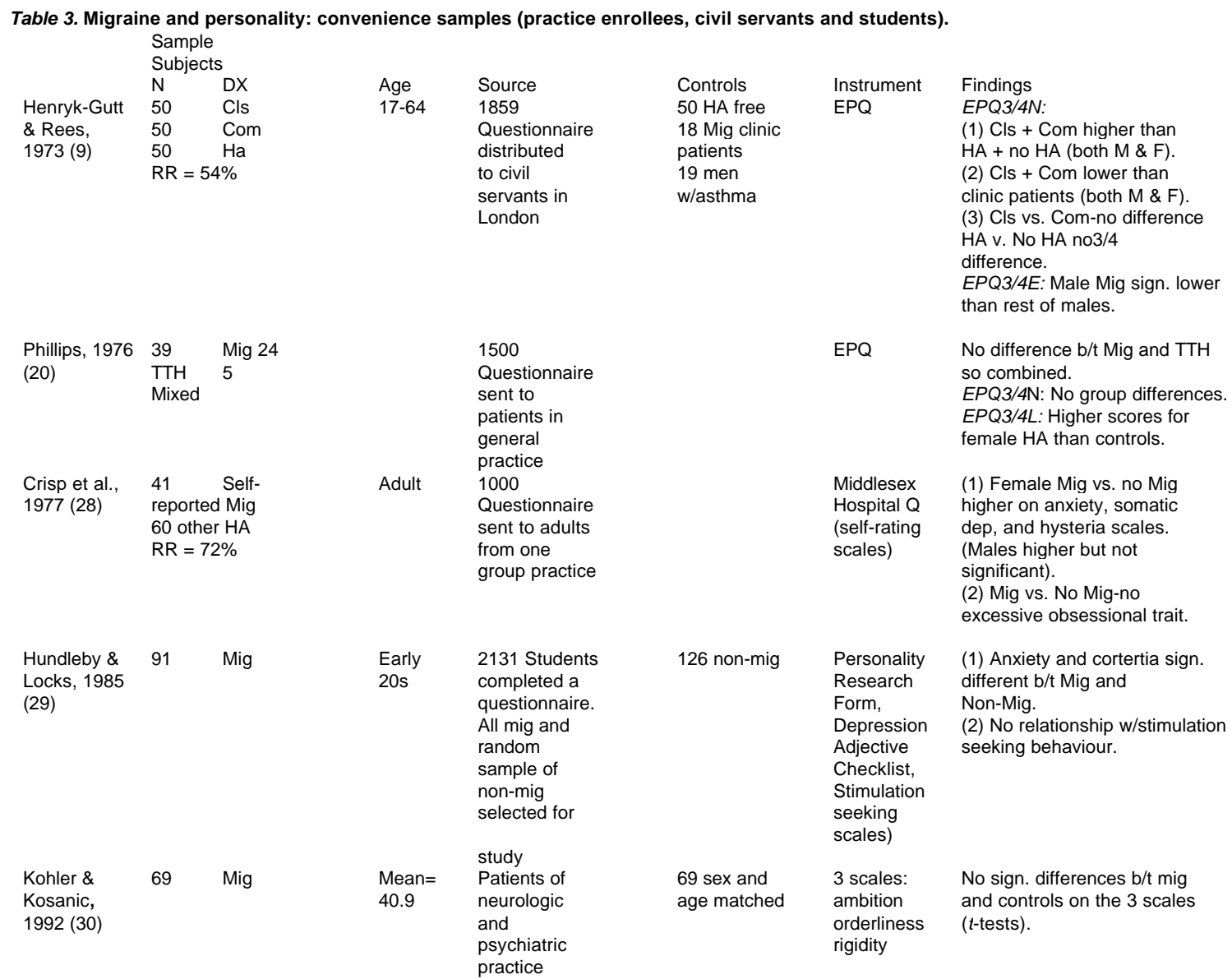

(29). The authors concluded that the differences, while detectable, were meager at best.

Köhler and Kosanic (30) found no difference between 69 migraineurs and age- and sex-matched controls in ambition, orderliness, and rigidity. Controls were patients from a neurologic and psychiatric practice; the patients had phobias, insomnia, or marital problems and agreed to fill out the personality questionnaire in the waiting room. This is clearly not a healthy control group.

In summary, studies that used the EPQ or similar personality measures and compared persons with migraine to non-migraine controls have reported an association between migraine and neuroticism (22, 24-26). (Results from one study (22) were consistent with this conclusion although not statistically significant.)

\section{MMPI studies (Table 4)}

Most investigators (31-34) have found that MMPI scores in migraineurs fall within the normal ranges, in contrast to the abnormalities found in patients with chronic TTH or mixed headache disorders (Table 4) (35). However, the original MMPI-I was developed on the basis of item responses from psychiatric patients (36) and has a distinct psycho-pathologic bias. It may not be sensitive to the personality traits found in non-psychiatric populations in general and in migraineurs specifically.

Kudrow and Sutkus (33) found that patients with migraine and cluster headache scored lowest, those with TTH and "combination headache" in the intermediate range, and those with post-traumatic headache scored highest on the neuroticism scales of 
Table 4. Migraine and personality: MMPI (neurotic triad ${ }^{\star}$ ) studies.

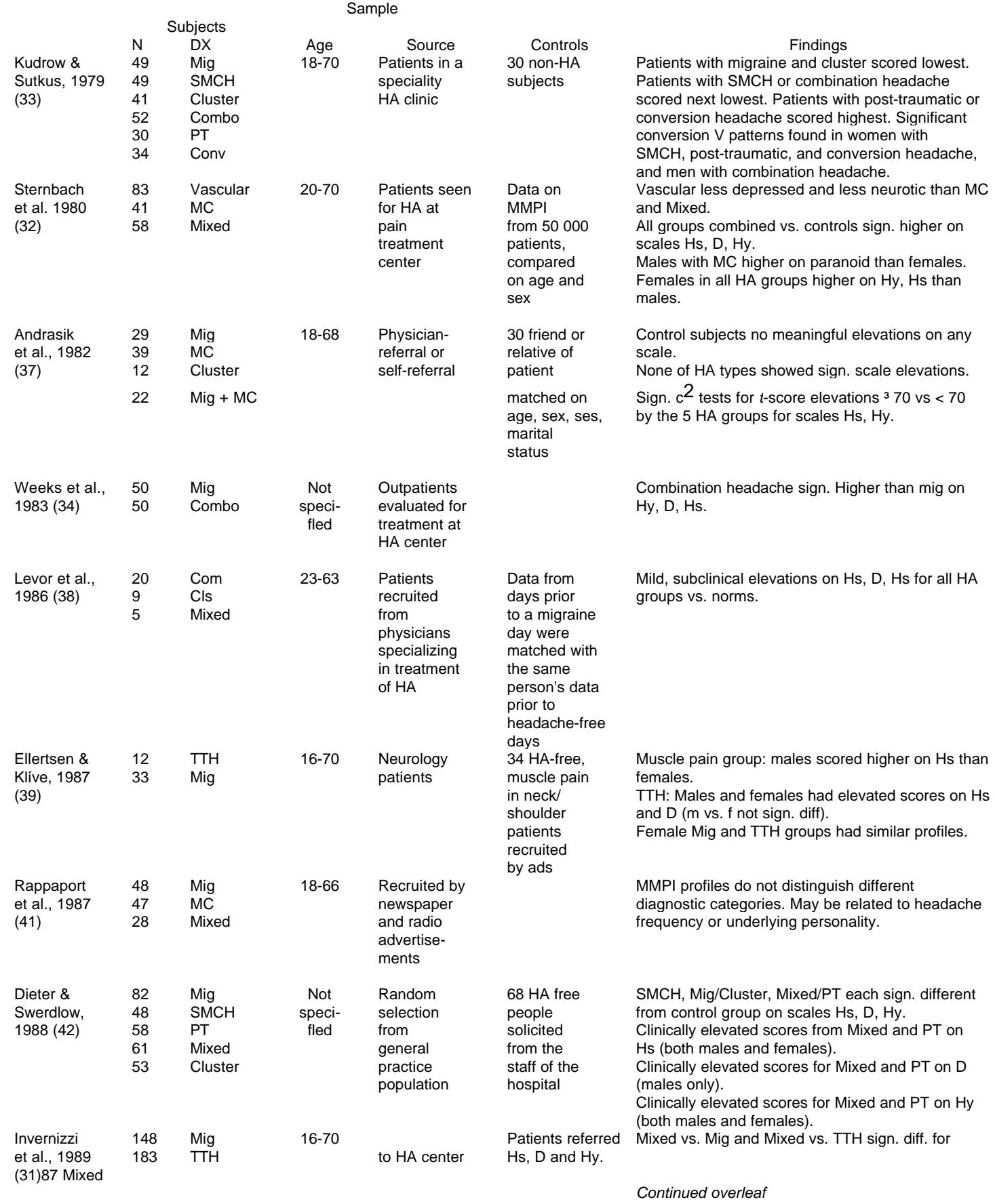




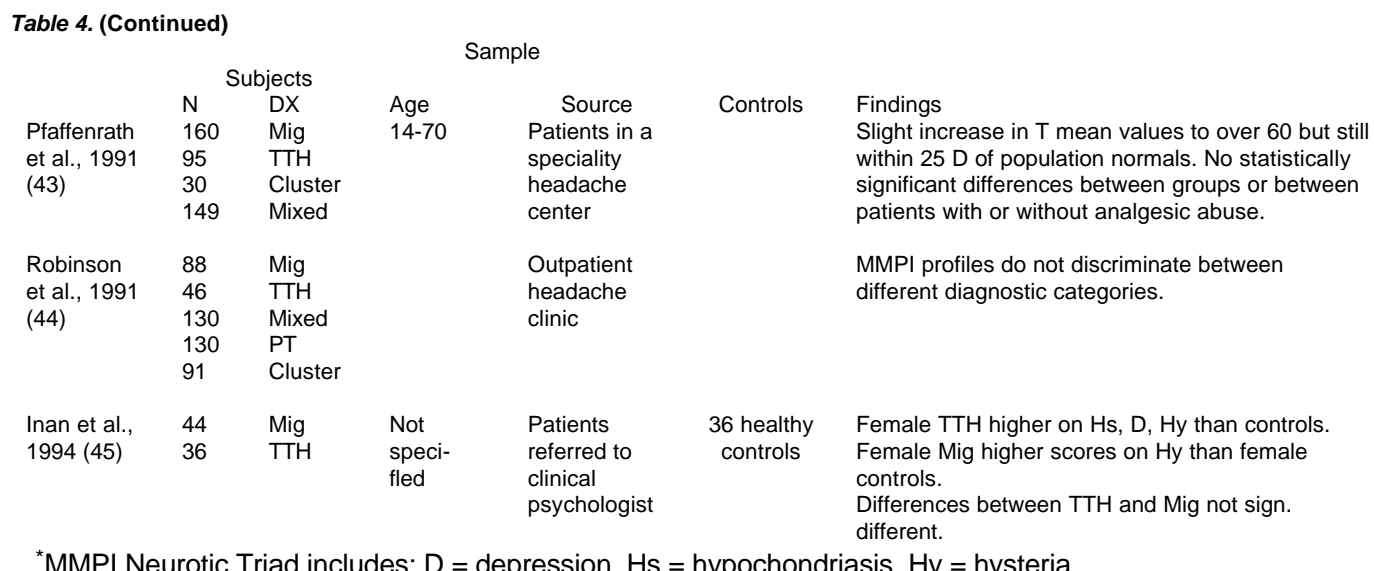

Abbreviations: $\mathrm{Com}=$ common migraine; $\mathrm{Cls}=$ classic migraine; Combo = combination; Conv $=$ conversion; $E P Q=$ Eysenck Personality Questionnaire; $E P Q-E=E P Q$ : Extraversion; $E P Q-N=E P Q$ : Neuroticism; EPQ-P = EPQ: Psychoticism; EPQ-L = EPQ: Lie; HA = headache; $M C$ = muscle contraction; Mig = migraine; Mixed = mixed headache type; $P T=$ post trauma; $R R=$ response rate; $S M C H=s c a l p$ muscle contraction; TTH = tension-type headache.

the MMPI. This is similar to the pattern found in chronic pain patients, who show characteristic "neurotic" MMPI profiles, with elevation of the first three clinical scales: Hypochondriasis (Hy), Depression (D), and Hysteria (Hs).

Sternbach et al. (32) studied 182 patients with vascular headache (migraine), muscle contraction headache, and mixed headache, and controls, and noted statistically significant differences on the MMPI in the Depression and Psychasthenia (anxiety) scales. While vascular headache patients tended to be less depressed and anxious than the muscle contraction and mixed headache group, the statistically significant differences were not considered clinically significant.

Andrasik et al. (37) compared 99 headache sufferers (participants in a research project) (migraine, muscle contraction, mixed, and cluster) to 30 matched non-headache controls using the Ad Hoc criteria. None of the headache types had significant scale elevations, although all possessed moderate elevations that increased in frequency, beginning with cluster and continuing through migraine, mixed, and muscle contraction headache.

Weeks et al. (34) compared, using standard norms and the Ad Hoc criteria, 50 migraineurs to 50 combination headache patients in a tertiary care center. Patients with combination headaches had higher scores than migraineurs on the Hs, D, and Hy scales. None of the T scores showed significant elevations above $>70$.

Levor et al. (38) studied 33 patients who had migraine, either with or without aura (common or classic, Ad Hoc criteria) recruited from physicians specializing in headache treatment. Twenty-four migraine patients also had muscle contraction headaches. These subjects had mild subclinical elevations of the Hs, D, and Hy scales.

Ellersten and Klíve (39) compared MMPI profiles in men and women with chronic muscle pain to the profiles of chronic tension-type headache patients and women migraineurs. Elevation of the Hs, D, and Hy subscales was found in all groups. A "conversion V" profile was found in women migraineurs but not in women with chronic tension-type headache.

Ellersten (40) prospectively studied a group of female migraineurs, comparing MMPI profiles before and after biofeedback and autogenic training. There were no differences on the MMPI between the most improved and the least improved patients before the start of treatment, suggesting that the MMPI has no value in predicting outcome. At 2 years, however, there were significant differences between these sub-groups. The most improved patients had significant improvement on five MMPI scales, suggesting that the headache disorder and the MMPI profile improve in parallel. The authors suggest that the psychologic problems reflected in the MMPI improve when the pain problems decrease, although other interpretations are possible. These findings suggest that the MMPI profile does not invariably reflect enduring personality characteristics; it may reflect "state" characteristics associated with having severe headache. The least improved group showed a slightly more elevated $\mathrm{V}$ configuration, but profiles were essentially unchanged. The resistant patients 
may continue to have the "state" characteristics associated with headache; alternatively they may have a comorbid psychiatric illness that is associated with abnormal MMPI profiles.

Rappaport et al. (41) compared MMPI profiles in headache sufferers who had IHS criteria migraine, muscle contraction, or mixed headaches. Within this headache population, four MMPI cluster profiles were found that did not correlate with their headache diagnosis.

Dieter and Swerdlow (42) found the MMPI profiles of 505 individuals with various headache diagnoses, including migraine, to be less pathologic than those reported in prior studies (Table 4). Clinically significant elevations of the $\mathrm{Hy}, \mathrm{D}$, and $\mathrm{Hs}$ scales occurred only in the post-traumatic and mixed headache groups. All five headache diagnoses had a significantly greater proportion of "conversion V" (muscle contraction headache $(12.5 \%)$, migraine $(18.3 \%)$, cluster headache $(20.7 \%)$, mixed headache $(24.6 \%)$, and post-traumatic headache $(31 \%)$ ), than headache-free controls $(0 \%)$. There were no significant differences among the headache conditions in "conversion V" frequency. (This is one of the few convenience-based samples with a control group.) When the items in the MMPI that address headache or their associated symptoms were deleted and the scores recalculated, there was a decrease in both the Hy and Hs scales to below the 70t clinical threshold. These data suggest that MMPI abnormalities result in part from accurate reporting of pain and its associated symptoms, and that there is a large intra-group variance in MMPI scores.

Invernizzi et al. (31) studied 418 patients with migraine, tension, and mixed headache, not using the IHS criteria. Patients with mixed headaches showed significantly elevated scores (Hs, D, Hy, and PT) on the MMPI compared to norms. Migraine and tension headache patients did not have elevated scores. No correlation was found between the MMPI scores and duration of illness.

Pfaffenrath et al. (43) studied 434 patients who had IHS classified cluster, migraine, or tension-type headache, or migraine and tension-type headache. The patients all had slightly elevated Hs, D, and Hy scales compared to test norms. No significant differences were found between patients who abused analgesics and those who did not.

Robinson et al. (44) attempted to see if there was any relationship between MMPI cluster profiles and the Ad Hoc criteria diagnostic categories. Cluster group analysis did not discriminate between different diagnostic categories. Differences may reflect patients' global response to pain rather than a headache-related personality.

Inan et al. (45) compared the MMPI profiles of Turkish women migraineurs with TTH patients and controls using the IHS criteria. Migraine sufferers had significantly higher scores on the hysteria sub-test, while TTH patients had higher scores on the neurotic subtests (Hy, D, and Hs).

Most MMPI studies have been clinic-based, limiting their generalizability and creating opportunities for selection bias. Some have not used control groups, relying instead on historical norms. Many have not used explicit diagnostic criteria for migraine. Despite these limitations, most studies show elevation of the neurotic triad, although this is not statistically significant.

Studies on migraine and personality have generally not controlled for drug use, headache frequency, or headache-related disability. One group found a slight non-significant increase in some T values of the MMPI in patients with drug abuse (44). Furthermore, they have not controlled for major psychiatric disorders (such as major depression or panic disorder), which occur more commonly in migraineurs (see next section). Comorbidity of migraine and major psychiatric disorders might confound the assessment of the relationship between migraine and personality traits. Neuroticism, in particular, is associated with depression and anxiety, which occur with increased prevalence in migraineurs (see next section). Differences in neuroticism across studies might reflect variations in the role of comorbid psychiatric disease. The available data suggest that migraineurs may be more neurotic than non-migraineurs. The stereotypical rigid, obsessional migraine personality might reflect the selection bias of a distinct subtype of migraine that is more likely to be seen in the clinic. Because of inconsistencies across studies, further research is needed before a definitive generalization can be made.

\section{Migraine and psychopathology and psychiatric disorders}

In contrast to the numerous studies on the relationship of migraine to personality traits or psychologic distress, there are only a few studies on the relationship of migraine to specific psychiatric disorders (46-53). Several clinic-based studies have reported an increased prevalence of migraine in patients with major depression and an increased prevalence of major depression in patients with migraine $(41,42)$. Three population-based studies have examined a wide range of psychiatric disorders in addition to major depression (43-47).

Merikangas et al. (43) reported on the association of migraine with specific psychiatric disorders in a random sample of 457 adults aged 27 to 28 years in Zurich, Switzerland. Persons with migraine $(n=61)$ were found to have increased 1-year rates of affective and anxiety disorders. Specifically, the odds ratio for major depression (OR $(2.2,95 \% \mathrm{Cl} 1.1$ - 
4.8)), bipolar spectrum disorders (OR $(2.9,95 \% \mathrm{Cl} 1.1-8.6)$ ), generalized anxiety disorder (OR $(2.7,95 \% \mathrm{Cl}$ 1.5-5.1)), panic disorder (OR (3.3, 95\% Cl 0.8-13.8)), simple phobia (OR (2.4, 95\% Cl 1.1-5.1)), and social phobia (OR (3.4, 95\% $\mathrm{Cl} 1.1-10.9)$ ) were significantly higher in persons with migraine compared to persons with no migraine. The odds ratio is used in retrospective case-controlled studies to approximate the relative risk. Because subjects in case-controlled studies are selected by the presence or absence of disease rather than by exposure status, the odds ratio is defined in terms of probabilities of exposure instead of probabilities of disease. The interpretation of the odds ratio is straightforward. The odds ratio for migraine and major depression implies that the odds of migraine are 2.2 times greater in persons with depression than in those without depression. Because the $95 \%$ confidence interval does not include 1.0, this difference is statistically significant at the $p=0.05$ level.

Migraine with major depression was frequently complicated by an anxiety disorder. In persons with all three disorders, Merikangas et al. suggest that the onset of anxiety generally precedes the onset of migraine, whereas the onset of major depression follows the onset of migraine. Merikangas believes that migraine associated with psychiatric morbidity may be a distinct syndrome, with different manifestations at different times in the life cycle. Anxiety may appear in early childhood, followed by migraine and then depression. Disease duration may be more important than attack frequency in determining the presence of associated psychologic conditions. If there is a subtype of migraine associated with anxiety and depression, it may require, or respond differently to, different treatment (44).

Stewart et al. (45) reported on the relationship of migraine to panic disorder and panic attacks in a population-based telephone interview survey of 10000 Washington County, Maryland residents aged 12 to 29 years. The highest rates of migraine headaches occurring in the last week were reported by men and women with a history of panic disorder. The proportion of migraine headaches reported by those with a history of panic attacks (who did not meet the criteria for panic disorder) was intermediate, whereas the proportion of migraine headaches in persons with no history of panic attacks was lowest. The relative risk of migraine headache during the previous week associated with a history of panic disorder was 6.96 in males and 3.70 in females. The associations of panic disorder and panic attacks with other types of headaches (i.e., muscle contraction symptoms, forehead pain only, and other) were considerably weaker (45).

Stewart et al. (46), in a follow-up study of the same population, found that $14.2 \%$ of women and $5.8 \%$ of men with a headache in the previous 12 months consulted a physician for the problem. An unexpectedly high proportion of those who consulted a physician for headache had a history of panic disorder. Of those who recently saw a physician, $15 \%$ of women and $12.8 \%$ of men between the ages of 24 and 29 years had a panic disorder. In contrast, only $5 \%$ of women and $3.1 \%$ of men in the same age group who had never seen a physician for headache had a history of panic disorder. This suggests that comorbid psychiatric disease is associated with seeking care for headache disorders and that the association between migraine and panic disorder would be overestimated in a clinic-based study (Berkson bias) (54).

Women with panic disorder who had recently seen a physician for headache had more severe, complex, frequent, and debilitating headaches, and often had extended disability. Migraine headache was very common (36\%) among those with panic disorder who sought care for headache. This epidemiologic study clearly demonstrates that a comorbid condition may be more highly, represented in a clinic-based population.

Breslau et al. (47) reported on the association of migraine (using the IHS criteria) with specific psychiatric disorders in a sample of 1007 young adults aged 21 to 30 years in southeast Michigan. Persons with a history of migraine $(n=128)$ had significantly higher lifetime prevalences of affective disorder, anxiety disorder, illicit drug-use disorder, and nicotine dependence. Sex-adjusted odds ratios were 4.5 for major depression $(95 \% \mathrm{Cl}$ 3.0-6.9), 6.0 for manic episode $(95 \% \mathrm{Cl} 2.0-18.0), 3.2$ for any anxiety disorder (95\% $\mathrm{Cl} 2.2-4.6)$, and 6.6 for panic disorder $(95 \% \mathrm{Cl} 3.2-13.9)(55)$. The psychiatric comorbidity odds associated with migraine with aura were generally higher than the comorbidity odds associated with migraine without aura (47). Migraine with aura was found to be associated with increased lifetime prevalence of suicidal ideation and attempts, controlling for sex, major depression, and other co-occurring psychiatric disorders (56).

Using follow-up data gathered 3.5 years after baseline, Breslau et al. (57) reported on the prospective relationship between migraine and major depression in their cohort of young adults. The relative risk for the first incidence of major depression during the follow-up period associated with prior migraine was $4.1(95 \% \mathrm{Cl}$ 2.2-7.4). The relative risk for first migraine during the follow-up period associated with prior major depression was $3.3(95 \% \mathrm{Cl} 1.6-6.6)$. Although the onset of migraine was reported to have preceded the onset of major depression in more than one-half of the comorbid cases, partially confirming the report by Merikangas et al. (42-44), the relative risk for the first onset of migraine in persons with prior major depression was nearly as high as the relative risk for the first onset of major depression in persons with prior migraine. 
In summary, recent epidemiologic studies support the association between migraine and major depression previously reported in clinic-based studies. Analysis of prospective data indicates that the observed cross-sectional or lifetime association between migraine and major depression could result from a bidirectional influence, from migraine to subsequent onset of major depression and from major depression to first migraine attack. Furthermore, these epidemiologic studies indicate that persons with migraine have increased prevalence of bipolar disorder, panic disorder, and one or more anxiety disorders. An association with illicit drug use disorder was reported by Breslau et al. (47), but this was not detected in the Zurich cohort surveyed by Merikangas et al. (43). An association with nicotine dependence reported by Breslau et al. (47) replicated previous reports of an increased prevalence of smoking in women with migraine $(58,59)$.

\section{Alternative explanations and suspected mechanism}

Associations between migraine and psychiatric disorders might be accounted for by two alternative explanations: (i) migraine is the cause of psycho-pathology or, conversely, is caused by it; and (ii) migraine and the psychiatric disorders associated with it have shared genetic or environmental risk factors.

Research to date has focused primarily on the migraine-major depression comorbidity. It has been proposed that major depression in persons with migraine might represent a psychologic reaction to repeated, disabling migraine attacks. Such an interpretation is consistent with the observation that, on the average, migraine has a younger age of onset than major depression and persons with comorbidity generally report an earlier age of onset of migraine than of major depression. Nonetheless, several lines of evidence suggest that, despite the typical chronologic pattern, major depression in comorbid cases cannot be adequately explained as a psychologic response to migraine attacks.

One line of evidence comes from a study of a biologic marker of depression in patients with migraine. Jarman et al. (60) administered the tyramine test to 40 migraine patients, 16 of whom had a lifetime history of major depression. Low tyramine conjugation, a trait marker for endogenous depression, was strongly associated with a lifetime history of major depression in subjects with comorbid disease, regardless of their current psychiatric status. The authors argue that the association of the trait marker with major depression in patients with migraine rules out the possibility that the depression is a psychologic reaction to migraine attacks.

A second line of evidence comes from the findings of Breslau et al. (51) demonstrating a bidirectional relationship between migraine and depression. In particular, the increased risk for the first onset of major depression in subjects with migraine weakens the hypothesis that major depression in persons with migraine is a psychologic response to disabling headache. The psychologic explanation for major depression associated with migraine would have predicted that the influence is only in one direction, that is, from migraine to subsequent major depression. Furthermore, Breslau and Davis (61) reported that the risk for new episodes of major depression (and/ or panic disorder) did not vary by the proximity of migraine attacks. Specifically, the incidence of major depression in persons whose last migraine attack had occurred more than 1 year before baseline was $15.4 \%$, compared to $13.1 \%$ in persons with migraine attacks during the preceding year. A higher incidence of new psychiatric disorders in persons with active compared to past migraine would have supported the secondary (reactive) depression hypothesis.

Despite several parallels between migraine and major depression in neurotransmitter abnormalities and pharmacologic treatment, there is little direct evidence of shared mechanisms $(62,63)$. Based on two family studies of the co-segregation of migraine with major depression, Merikangas et al. (44) reported that there was no evidence that the association between the two disorders was transmissible within families by genetic or environmental mechanisms. It is possible that both disorders are accounted for by a common underlying condition. One possibility is that dysregulation in a neurochemical system within the brain, for example the serotonergic system, gives rise to both disorders. It is also possible that each condition somehow increases the risk for the other $(56,57,64)$. The data regarding these choices are not clear at this time.

\section{References}

1. Pope A. The rape of the lock. In: Swallow A, editor. The Rinehart book of verse. New York: Holt, Rinehart, and Winston, 1962:148-9

2. Wolff HG. Personality features and reactions of subjects with migraine. Arch Neurol Psychiatry 1937;37:895-921

3. Lipton RB, Stewart WF, Celentano DD, Reed Al. Undiagnosed migraine: a comparison of symptom-based and self-reported physician diagnosis. Arch Int Med 1992:156:1-6

4. $\quad$ Lipton RB, Stewart WF. Health care use for migraine. Submitted for publication, 1994

5. Linet MS, Stewart WF. Migraine headache: epidemiologic perspectives. Epidemiol Rev 1984;6:107-39

6. Liner MS, Stewart WF, Celentano DD, Ziegler D, Sprecher M. An epidemiologic study of headache among adolescents and young adults. JAMA 1989;261:2211-6

7. Silberstein SD, Lipton R. The epidemiology of migraine. Neuroepidemiology 1993;12:179-94

8. Lipton RL, Silberstein SD. Why study the comorbidity of migraine? Neurology 1994;44:54-5 
Henryk-Gutt R, Rees WL. Psychological aspects of migraine. J Psychosom Med 1973;17:141-53

Friedman AP, Finley KH, Graham JR. Classification of headache. Arch Neurol 1962;6:173-6

11. Headache Classification Committee of the International Headache Society. Classification and diagnostic criteria for headache disorders, cranial neuralgia, and facial pain. Cephalalgia 1988;8 Suppl 7:1-96

12. Lipton RB, Stewart WF, Merikangas KR. Reliability in headache diagnosis. Cephalalgia 1993;13 Suppl 12:29-33

13. Merikangas KR, Frances A. Development of diagnostic criteria for headache syndromes: lessons from psychiatry. Cephalalgia 1993;13 Suppl 12:34-8

14. Adler CS, Adler SM. The migraine patient: descriptive studies. In: Adler CS, Adler SM, Packard RC, editors. Psychiatric aspects of headache. Baltimore: Williams \& Wilkins, 1987:131-41

15. Gelfand R. Glossary. In: Kaplan HI, Freedman AM, Sadock BJ, editors. Comprehensive textbook of psychiatry (3rd ed). Baltimore: Williams \& Wilkins, 1980:3306-65

16. Cattell RB. Personality theory derived from quantitative experiments. In: Kaplan HI, Freedman AM, Sadock BJ, editors. Comprehensive textbook of psychiatry (3rd ed). Baltimore: Williams \& Wilkins, 1980:848-68

17. Schmidt FN, Carney P, Fitzsimmons G. An empirical assessment of the migraine personality type. J Psychosom Res 1986;30:189-97

18. Touraine GA, Draper G. The migrainous patient: a constitutional study. J Nerv Ment Dis 1934;80:1-204

19. Friedman AP, Merritt HH. Migraine. In: Friedman AP, Merritt HH, editors. Headache, diagnosis and treatment. Philadelphia: FA Davis, 1959:201-49

20. Didion J. In bed. In: The white album. New York: Farrar, Straus, and Giroux, 1979

Brandt J, Celentano D, Stewart WF, Liner M, Folstein MF. Personality and emotional disorder in a community sample of migraine headache sufferers. Am J Psychiatry 1990;147: 303-8

Rasmussen BK. Migraine and tension-type headache in a general population: psychosocial factors. Int J Epidemiol 1992;21:1138-43

Merikangas KR, Stevens DE Angst J. Headache and personality: results of a community sample of young adults. J Psychiatr Res 1993;27:187-96

Passchier J, Orlebeke JF. Headaches and stress in schoolchildren: an epidemiological study. Cephalalgia 1985;5:167-76

Passchier J, van der Helm-Hylkema H, Orlebeke JF. Personality and headache type: a controlled study. Headache 1984;24:140-6

Philips C. Headache and personality. J Psychosom Res 1976;20:535-42

Silberstein SD. Chronic daily headache and tension-type headache. Neurology 1993;43:1644-9

Crisp AH, Kalucy RS, McGuinness B, Ralph PC, Harris G. Some clinical, social and psychological characteristics of migraine subjects in the general population. Postgrad Med $J$ 1977;53:691-7

Hundleby JD, Loucks AD. Personality characteristics of young adult migraineurs. J Pers Assess 1985;49:497-500

Köhler T, Kosanic S. Are persons with migraine characterized by a high degree of ambition, orderliness, and ridigity? Pain 1992;48:321-3

Invernizzi G, Gala C, Buono M, Cittone L, Tavola T, Conte G. Neurotic traits and disease duration in headache patients. Cephalalgia 1989:9:173-8

Sternbach RA, Dalessio DJ, Kunzel M, Bowman GE. MMPI patterns in common headache disorders. Headache 1980;20: 311-5

Kudrow L, Sutkus BJ. MMPI pattern specificity in primary headache disorders. Headache 1979;19:18-24

Weeks R, Baskin S, Sheftell F, Rapoport A, Arrowsmith F. A comparison of MMPI personality data and frontalis electromyographic readings in migraine and combination headache patients. Headache 1983;23:75-82

Stewart WF, Liner MS, Celentano DD, Van Natta M, Ziegler D. Age and sex-specific incidence rates of migraine with and without visual aura. Am J Epidemiol 1991;34: 1111-20

Greene RL. The MMPI: an interpretive manual. New York: Grune \& Stratton, 1980

Andrasik F, Blanchard EB, Arena JG, Teders SJ, Teevan RC, Rodichok MD. Psychologic functioning in headache sufferers. Psychosom Med 1982;44:171-82

Levor RM, Cohen MJ, Naliboff BD, McArthur D. Psycho-social precursors and correlates of migraine headache. J Consult Clin Psychol 1986;54:347-53

Ellertsen B, KI(\&)ve H. MMPI patterns in chronic muscle pain, tension headache, and migraine. Cephalalgia 1987;7:65-71

Ellersten B. Personality factors in recurring and chronic pain. Cephalalgia 1991;12:129-32.

Rappaport NB, McAnulty DP, Waggoner CD, Brantley PJ. Cluster analysis of Minnesota Multiphasic Personality Inventory (MMPI) profiles in a chronic headache population. J Behavioral Med 1987;10:49-61

Dieter JN, Swerdlow B. A replicative investigation of the reliability of the MMPI in the classification of chronic headaches. Headache 1988;28:212-22

Pfaffenrath V, Hummelsberger J, Pöllmann J, Kaube H, Rath M. MMPI personality profiles in patients with primary headache syndromes. Cephalalgia 1991;11:263-8

Robinson ME, Geisser ME, Dieter JN, Swerdlow B. The relationship between MMPI cluster membership and diagnostic category in headache patients. Headache 1991;31: 111-5

Inan L, Soykan C, Tulunay FC. MMPI profiles of Turkish headache sufferers. Headache 1994;34:152-4

Marchesi C, De Ferri A, Petrolini N, Gobi A, Manzoni GC, Boiro V, De Risio C. Prevalence of migraine and muscle tension headache in depressive disorders. J Affect Dis 1989; 16:33-6

Morrison DP, Price WH. The prevalence of psychiatric disorder among female new referrals to a migraine clinic. Psychol Med 1989;19:919-25

Merikangas KR, Risch NJ, Merikangas JR, Weissman MM, Kidd KK. Migraine and depression: association and familial transmission. J Psychiatr Res 1988;22:119-29

Merikangas KR, Angst J, Isler H. Migraine and psycho-pathology. Results of the Zurich cohort study of young adults. Arch Gen Psychiatry 1990;47:849-53

Merikangas KR, Merikangas JR, Angst J. Headache syndromes and psychiatric disorders: association and familial transmission. J Psychol Res 1993;27:197-210

Stewart WF, Liner MS, Celentano DD. Migraine headaches and panic attacks. Psychosom Med 1989;51:559-69

Stewart WF, Schechter A, Liberman J. Physician consultation for headache pain and history of panic: results from a population-based study. Am J Med 1992;91:35S-40S

Breslau N, Davis GC, Andreski P. Migraine, psychiatric disorders and suicide attempts: an epidemiological study of young adults. Psychiatry Res 1991;37:11-23

Berkson J. Limitations of the application of four-fold table analysis to hospital data. Biometrics Bull 1949;2:47-53

Breslau N, Davis GC. Migraine, physical health and psychiatric disorders: a prospective epidemiologic study of young adults. J Psychiatric Res 1993;27:211-21

Breslau N. Migraine, suicidal ideation, and suicide attempts. Neurology 1992;42:392-5

Breslau N, Davis GC, Schultz LR, Peterson EL. Migraine and major depression: a longitudinal study. Headache 1994; 7:387-93 
58. Markush RE, Karp HR, Heyman A, O'Fallon WM. Epidemiologic study of migraine symptoms in young women. Neurology 1975;25:430-5

59. Paulin JM, Waal-Manning HJ, Simpson FO, Knight RG. The prevalence of headache in a small New Zealand town. Headache 1985;25:147-51

60. Jarman J, Fernandez M, Davies PTG, Glover V, Steiner TJ, Thompson C, et al. High incidence of endogenous depression in migraine: confirmation by tyramine test. J Neurol Neurosurg Psychiatry 1990;53:573-5

61. Breslau N, Davis GC. Migraine, major depression and panic disorder: a prospective epidemiologic study of young adults. Cephalalgia 1992;112:85-9

62. Gordon ML, Lipton RB, Brown SL, et al. Headache and cortical responses to m-chlorophenylpiperazine are highly correlated. Cephalalgia 1993;13:400-5

63. Post RM, Silberstein SD. Shared mechanisms in affective illness, epilepsy, and migraine. Neurology 1994;44:S37-47

64. Silberstein SD. Serotonin and migraine. Headache 1994;7: 408-17 